\title{
ASSESSMENT FOR LEARNING DALAM MODEL PEMAHAMAN PIRIE \& KIEREN
}

\author{
Ramadhan Kurnia Habibie ${ }^{1}$, Turmudi ${ }^{2}$ \\ ${ }^{1}$ Universitas Lampung, ${ }^{2}$ Universitas Pendidikan Indonesia \\ ${ }^{1}$ ramadhan.kurnia2318@fkip.unila.ac.id
}

\begin{abstract}
So far the learning assessment developed in elementary schools is only limited to the assessment of learning outcomes. The test instrument used only measures cognitive abilities and results in learning outcomes scores that cannot be used to measure students' abilities comprehensively. Assessment for learning is a learning assessment paradigm that can produce a comprehensive picture of students' abilities and can be used to improve the learning process on an ongoing basis. This study aims to describe the form of assessment for learning on Pirie \& Kieren's understanding models in mathematics learning. This research is qualitative research using a case study approach. Data in this study were collected through direct observation of critical events, document inspection of written test results, and semi-structured interviews of research subjects. The data is analyzed qualitatively including category collection, direct interpretation, pattern formation, and naturalistic generalization. The credibility of the data in this study was verified using the data triangulation method. The results showed that the research subjects were in the formalizing layer in the learning of quadrilateral. In the image having layer research subjects experienced obstacles and folding back to the image making layer to reconstruct her understanding. Unfortunately, the formalizing layer of research subjects again experienced obstacles that resulted in it not being able to grow to the next layer. Through the use of the assessment approach for learning in the Pirie-Kieren understanding model, it can be seen that students' abilities comprehensively and the obstacles experienced during the learning process take place.

Keywords: Assessment for learning; folding back; layer of understanding; Pirie \& Kieren
\end{abstract}

\begin{abstract}
Abstrak
Selama ini asesmen pembelajaran yang berkembang di Sekolah Dasar hanya sebatas penilaian hasil belajar. Instrumen tes yang digunakan hanya mengukur kemampuan kognitif dan berujung pada skorskor hasil belajar yang tidak dapat digunakan untuk mengukur kemampuan siswa secara komprehensif. Assessment for learning merupakan paradigma asesmen pembelajaran yang dapat menghasilkan gambaran kemampuan siswa secara komprehensif dan dapat digunakan untuk memperbaiki proses pembelajaran secara berkelanjutan. Penelitian ini bertujuan untuk mendeskripsikan bentuk assessment for learning dalam model pemahaman Pirie \& Kieren pada pembelajaran matematika. Penelitian ini merupakan penelitian kualitatif dengan menggunakan pendekatan studi kasus. Data dalam penelitian ini dikumpulkan melalui pengamatan langsung terhadap peristiwa-peristiwa kritis, inspeksi dokumen hasil tes tertulis, dan wawancara semiterstruktur terhadap subyek penelitian. Data tersebut dianalisis secara kualitatif meliputi pengumpulan kategori, interpretasi langsung, pembentukan pola, hingga generalisasi naturalistik. Kredibilitas data dalam penelitian ini diverifikasi dengan menggunakan metode triangulasi data. Hasil penelitian menunjukkan bahwa subjek penelitian berada pada lapisan formalizing dalam pembelajaran luas segiempat. Pada lapisan image having subyek penelitian mengalami hambatan dan melakukan folding back ke lapisan image making untuk mengkonstruksi kembali pemahamannya. Sayangnya pada lapisan formalizing subyek penelitian kembali mengalami hambatan yang mengakibatkannya tidak dapat tumbuh ke lapisan selanjutnya. Melalui penggunaan pendekatan asesmen for learning dalam model pemahaman Pirie \& Kieren dapat diketahui kemampuan siswa secara komprehensif serta hambatan yang dialami selama proses pembelajaran berlangsung.
\end{abstract}

Kata Kunci: assessment for learning; folding back; lapisan pemahaman; Pirie \& Kieren

\begin{tabular}{llll}
\hline Received & $: 2020-06-20$ & Approved & $: 2020-11-30$ \\
Reviesed & $: 2020-11-29$ & Published & $: 2021-01-31$ \\
\hline
\end{tabular}

Jurnal Cakrawala Pendas is licensed under a Creative Commons Attribution-

ShareAlike 4.0 International License. 


\section{Pendahuluan}

Pendidikan di Indonesia dewasa ini semakin berkembang dalam berbagai aspek. Perkembangan tersebut salah satunya terjadi pada aspek proses pembelajaran, termasuk pembelajaran matematika. Pembelajaran matematika dikembangkan banyak peneliti dengan menggunakan teori, metode, dan model belajar yang beraneka ragam. Namun sayangnya perkembangan tersebut tidak diikuti dengan perubahan prinsip asesmen pembelajaran di lapangan. Selama ini asesmen pembelajaran yang berkembang di Sekolah Dasar hanya sebatas penilaian hasil belajar. Instrumen tes yang digunakan hanya mengukur kemampuan kognitif dan berujung pada skor-skor hasil belajar yang tidak dapat digunakan untuk mengukur kemampuan siswa secara komprehensif. Bahkan sistem asesmen tersebut mampu merubah esensi pembelajaran dari meningkatkan potensi siswa secara berkelanjutan menjadi sebuah kegiatan intensif pengerjaan soal-soal latihan suatu ujian tertentu.

Praktek pembelajaran tersebut tentunya saat ini sudah tidak sesuai dengan Peraturan Menteri Pendidikan dan Kebudayaan RI Nomor 43 tahun 2019 tentang Penyelenggaraan Ujian yang Diselenggarakan Satuan Pendidikan dan Ujian Nasional. Peraturan tersebut merupakan sebuah instruksi tertulis dari negara kepada semua guru untuk merubah paradigma asesmen pembelajaran yang selama ini mereka lakukan. Proses pembelajaran harus kembali pada fungsi awalnya yaitu meningkatkan potensi siswa secara optimal dan berkelanjutan (Bird \& Yucel, 2013). Sistem asesmen pembelajaran yang digunakan juga harus sesuai dengan kebutuhan tersebut. Oleh karena itu guru memerlukan informasi baru tentang asesmen pembelajaran yang dapat diterapkan di dalam kelas.

Asesmen merupakan bagian yang tidak terpisahkan dalam proses pembelajaran. Asesmen merupakan proses merencanakan, memperoleh, dan menyediakan informasi bagi guru untuk membuat keputusan alternatif dalam proses pembelajaran yang sedang berlangsung maupun yang akan dating (Sawant, 2016). Peran asesmen bukan hanya sebagai bagaian dalam pembelajaran, tetapi asesmen mempunyai fungsi penting untuk pembelajaran itu sendiri. Penilaian hasil belajar dalam bentuk tes tertulis yang berkembang hanya mengukur kemampuan kognitif saja. Akibatnya pembelajaran yang dilakukan hanya sebatas kegiatan latihan intensif soal dengan menghafal rumus matematika saja (Yanto et al., 2020). Tes tertulis tidak dapat digunakan untuk mengukur kemampuan siswa secara komprehensif, meskipun demikian tes tersebut tetap berguna untuk mengukur penguasaan basis pengetahuan siswa. Oleh karena itu pembelajaran yang sepenuhnya mengacu kepada tes tidak akan memberi nilai yang positif bagi kemajuan siswa.

Berbeda dengan assessment for learning yang dapat digunakan untuk mengukur kemampuan siswa secara komprehensif, baik keterampilan dasar, proses, maupun investigasi siswa (Subali, 2015). Assessment for learning didasarkan pada pemahaman bahwa proses pembelajaran dapat dan harus terjadi melalui proses asesmen. Assessment for learning merupakan bentuk asesmen yang dilakukan untuk perbaikan pembelajaran tidak sekedar alat untuk melihat banyaknya pengetahuan yang dimiliki oleh siswa (Budiyono, 2015). Siswa diposisikan sebagai mitra dalam proses pembelajaran yang memiliki unsur kepentingan dan tanggungjawab terhadap pembelajaran mereka sendiri. Siswa diharapkan dapat melakukan evaluasi terhadap dirinya sendiri (self assessment), sehingga mereka akan lebih memahami soal (permasalahan) yang telah dihadapinya (Wulandari, 2016; Martin-Kniep \& R, 2017). Guru mempunyai tugas untuk melakukan apresiasi terhadap kapasitas siswa demi mendukung peningkatan kemampuan siswa dalam melakukan asesmen evaluatif (Thomson, 2013). 
Hasil belajar siswa merupakan komponen penting dalam upaya peningkatan kualitas pembelajaran. Hasil belajar yang diperoleh siswa dapat dijadikan umpan balik dalam proses mengambil keputusan untuk perbaikan proses pembelajaran (Hill \& Edwards, 2019). Variasi dalam penyampaian umpan balik akan secara langsung mempengaruhi hasil belajar siswa dan kemampuan siswa secara keseluruhan (Bird \& Yucel, 2013). Assessment for learning akan mengembangkan kemampuan asesmen siswa saat mereka menjadi evaluator atas pekerjaan mereka sendiri dan orang lain (Sadler, 1989; Winarno et al., 2019). Pengembangan umpan balik guru dan siswa akan menjadi faktor penentu peningkatan kualitas pembelajaran dan kompetensi siswa (Carless, 2017). Penerapan assessment for learning dalam pembelajaran matematika dapat meningkatkan motivasi, kepercayaan diri, kesadaran diri, perilaku siswa selama belajar, dan kemampuan dalam matematika (Winarno et al., 2019).

Salah satu komponen kemampuan dalam matematika adalah pemahaman matematika itu sendiri. Pemahaman merupakan suatu proses bukan sebagai perolehan yang konstan (Gulkilik et al., 2020). Pertumbuhan pemahaman matematika merupakan suatu proses yang dinamis, aktif, kontinu, tetapi tidak linier dan bersifat rekursif, serta melibatkan lingkungan belajar dan respon dari ekosistem belajar itu sendiri (Pirie \& Kieren, 1994; Wright, 2014; Sengul \& Yildiz, 2016). Rekursif mempunyai arti pada suatu titik pemahaman seseorang merupakan cakupan dari pengetahuan dan pemahaman sebelumnya dan memiliki kesamaan struktur (Kieren \& Pirie, 1991). Pemahaman matematika ini terbentuk berdasarkan pemahaman awal (lapisan dalam) yang akan berulang dalam menumbuhkan pemahaman lanjutan (lapisan luar) dan dibatasi sesuai proses dan bentuk di dalamnya (Kieren \& Pirie, 1991). Model pemahaman Pirie \& Kieren membagi pertumbuhan pemahaman matematika dalam beberapa lapisan pemahaman, yaitu: primitive knowing, image making, image having, property noticing, formalizing, observing, structuring, dan inventizing (Pirie \& Kieren, 1994).

Pemahaman matematika tidak melalui jalur yang linier, terdapat peninjauan kembali pada tingkat pemahaman sebelumnya untuk membangun tingkat pemahaman baru (Kieren \& Pirie, 1991; Pirie \& Martin, 2000; Martin et al., 1970). Pengetahuan baru muncul dengan memanggil pengetahuan lama dan tumbuh secara berkelanjutan (Kieren \& Pirie, 1991; L. C. Martin, 2008). Proses tersebut dinamakan folding back, dimana dilakukan peninjauan kembali pada lapisan pemahaman yang lebih dalam, mengambil pengetahuan primitif, membuat atau memiliki gambar baru, atau melihat properti baru dan mempertebal pemahaman sebelumnya (Pirie \& Martin, 2000; L. Martin et al., 2005). Proses folding back merupakan strategi konstruktif yang dilakukan untuk memperluas dan mengembangkan pemahaman yang ada agar dapat memadai untuk menyelesaikan masalah yang baru ditemukan (L. Martin et al., 2005; Wright, 2014).

Proses folding back tidak akan berjalan efektif apabila pemahaman matematika yang coba dikumpulkan pada lapisan lebih dalam tidak mencukupi untuk digunakan pada masalah yang dihadapi. Pada bagian ini, siswa diharapkan dapat mengenali keterbatasan pemahaman matematika mereka sendiri dan cara yang paling tepat untuk mengatasinya (L. C. Martin, 2008). Intervensi dari guru merupakan sesuatu yang penting dalam memastikan bentuk folding back yang dilakukan siswa sudah sesuai dan dapat memfasilitasi hasil yang efektif ((L. C. Martin, 2008; Wright, 2014). Guru dapat menjadi stimulus dengan memberikan "ruang berpikir" untuk siswa agar dapat menyadari potensi pemahaman yang dimilikinya dan menentukan sendiri bentuk folding back yang paling sesuai untuk dirinya. Sebuah bentuk instruksi langsung dari guru maupun bentuk pemberhentian "ruang berpikir" siswa dapat menyebabkan diskontinuitas pada pemahaman matematika siswa (L. C. Martin, 2008). Model Pirie-Kieren menyediakan kerangka kerja untuk memetakan tindakan siswa dalam berbagai 
konteks, menelusuri gerakan yang dinamis di antara delapan tingkat pemahaman. Penelusuran dilakukan dalam tahapan siswa membangun, mencari, dan mengumpulkan ide. Lapisan-lapisan teori Pirie-Kieren berkembang dari yang konkret ke abstrak, atau dari yang spesifik ke umum (L. Martin et al., 2005). Keberhasilan pertumbuhan pemahaman matematika siswa bergantung pada intervensi yang dilakukan oleh guru baik pemilihan masalah, situasi, maupun strategi (Wright, 2014).

Proses psikologis yang terlibat dalam memahami objek linguistik maupun konseptual matematika dimediasi oleh makna institusional, yaitu instrumen semiotik, kebiasaan, dan konvensi bersama. Proses psikologis tersebut dipengaruhi oleh lingkungan perkembangan dan budaya yang berbeda. Seperti asesmen dalam proses pembelajaran, pemahaman matematika dalam pembelajaran matematika merupakan hal yang tidak terpisahkan. Pemahaman matematika merupakan landasan bagi siswa untuk melakukan berbagai macam aktivitas matematika lainnya. Sebagai suatu ilmu yang bersifat simbolis, matematika tidak akan bermanfaat tanpa logika berfikir yang benar (Ayuningsih et al., 2019). Melalui gambaran aktivitas dari tiap lapisan pemahaman (acting dan expressing) serta aktivitas folding back dalam memahami suatu konsep matematika bentuk assessment for learning dapat ditemukan. Investigasi proses berpikir atau hasil dari proses berpikir diperlukan untuk dapat merefleksikan sejauh mana penguasaan pemahaman konsep siswa (Syamsuri et al., 2018). Pengetahuan yang mendalam tentang proses pemahaman siswa dapat dimanfaatkan oleh guru untuk memperbaiki metode pengajaran agar lebih efektif (Valcare et al., 2013).

Penelitian ini merupakan suatu respon terhadap kebutuhan tersebut dan bertujuan untuk mendeskripsikan bentuk assessment for learning yang dapat diimplementasikan dalam proses pembelajaran di kelas. Penelitian ini menghadirkan model pemahaman Pirie \& Kieren dalam pembelajaran matematika melalui sudut pandang assessment for learning. Deskripsi setiap aktifitas (acting dan expressing) yang terjadi pada masing-masing lapisan pemahaman digunakan sebagai rujukan gambaran kemampuan siswa secara komprehensif. Informasi yang diperoleh dapat digunakan sebagai dasar poin-poin utama yang harus diperhatikan dalam meningkatkan kualitas pembelajaran selanjutnya. Gambaran assessment for learning secara utuh dalam model pemahaman Pirie \& Kieren yang dijabarkan dalam penelitian ini dapat digunakan sebagai salah satu sumber informasi bagi para guru terhadap alternatif bentuk asesmen pembelajaran.

\section{Metode Penelitian}

Penelitian ini merupakan penelitian kualitatif dengan menggunakan metode studi kasus. Kasus yang diambil adalah kegiatan pembelajaran matematika di SDN Balongsari II Megaluh Jombang. Fokus penelitian ini adalah sudut pandang assessment for learning dalam model pemahaman Pirie \& Kieren yang diimplementasikan dalam pembelajaran matematika (luas segiempat) di Kelas V SDN Balongsari II Megaluh Jombang. Subjek utama dalam penelitian ini adalah siswa yang mencapai lapisan pemahaman tertinggi dari tes pemahaman matematika yang dilakukan sebelum pembelajaran luas segiempat berlangsung. Proses analisis dalam isu utama penelitian ini dilakukan secara intensif, terperinci, dan mendalam. Berbagai macam gambaran model pemahaman yang muncul dari subyek penelitian baik acting maupun expressing serta folding back pada setiap lapisan pemahaman yang dicapai dijabarkan kembali melalui sudut pandang assessment for learning.

Peneliti adalah instrumen utama dalam penelitian ini. Data dalam penelitian ini dikumpulkan melalui pengamatan langsung terhadap peristiwa-peristiwa kritis, inspeksi 
dokumen hasil tes tertulis, dan wawancara semi-terstruktur terhadap subyek penelitian dengan perpaduan sudut pandang etic dan emic. Dokumen yang dikumpulkan dalam penelitian ini merupakan hasil pekerjaan subjek penelitian terhadap instrumen tes tertulis pertumbuhan pemahaman luas segiempat. Selain itu dokumen yang dikumpulkan berupa rekaman dalam bentuk video terkait aktivitas belajar siswa selama proses pembelajaran luas segiempat. Pada kegiatan wawancara, data digali sedalam mungkin untuk mendapatkan fakta-fakta kritis dan unik yang didapatkan dalam kegiatan pengamatan langsung maupun inspeksi dokumen hasil tes tertulis. Data tersebut dianalisis secara kualitatif dengan pendekatan interpretasional meliputi pengumpulan kategori, interpretasi langsung, pembentukan pola, hingga generalisasi naturalistik (Gall et al., 2003).

Kredibilitas data dalam penelitian ini diverifikasi dengan teknik triangulasi data temuan. Triangulasi dilakukan dengan teknik triangulasi narasumber, teknik pengumpulan data, dan waktu. Data yang sudah diperoleh oleh peneliti dikonfirmasikan kepada informan untuk mencegah adanya bias makna dari temuan penelitian. Selanjutnya peneliti melakukan konfirmasi data penelitian dari 3 sumber pengumpulan data yang meliputi pengamatan langsung, inspeksi dokumen tes tertulis, dan wawancara semi-terstruktur. Selain itu peneliti membuat rantai bukti dengan mencatat semua data yang dikumpulkan dalam penelitian ini, orang-orang yang terlibat dalam pengumpulan data, dan tanggal pengumpulan data. Peneliti menulis sketsa terperinci dari insiden kritis dalam rangkaian penelitian ini. Temuan dari penelitian ini dilaporkan pada ahli untuk dievalusi dan disempurnakan demi memperkuat konstruksi teori yang dibangun.

\section{Hasil dan Pembahasan}

Sesuai dengan teori yang dikemukakan oleh Pirie \& Kieren (1994), pertumbuhan pemahaman bersifat dinamis, kontinu, tetapi tidak linier. Ketidaklinieran tersebut akibat adanya beberapa inhibitor yang menghambat subjek penelitian tumbuh ke lapisan pemahaman yang lebih dalam dan harus melakukan aktivitas folding back untuk mengumpulkan informasi di lapisan sebelumnya.

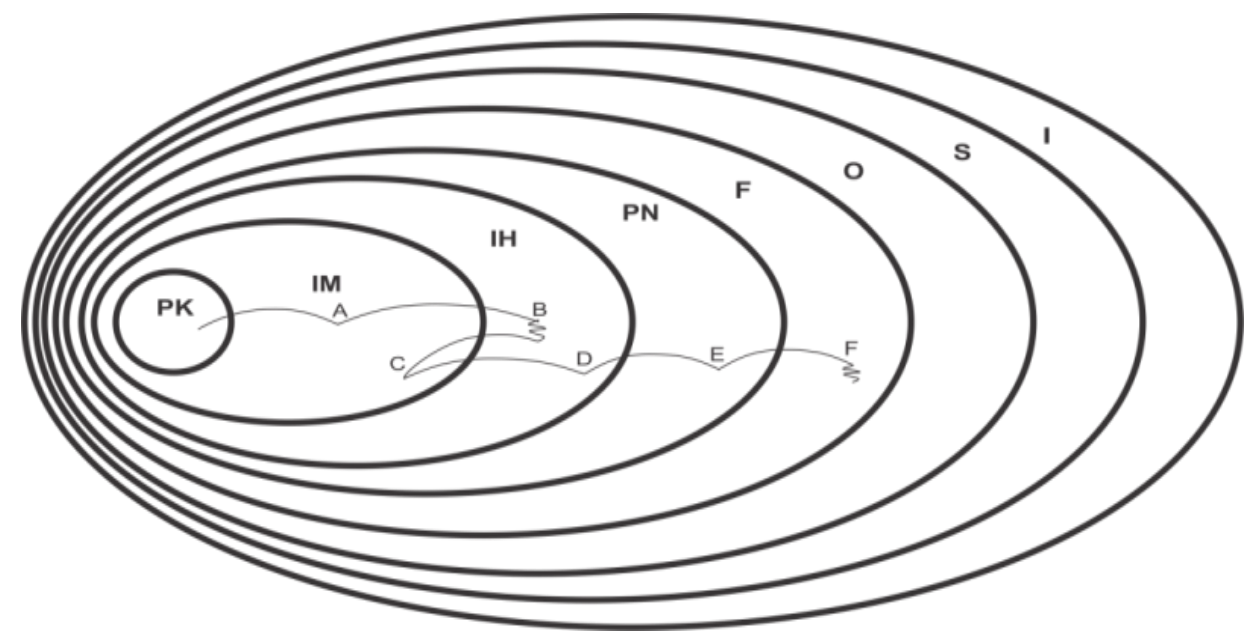

Gambar 1. Pertumbuhan Pemahaman Matematika Subjek pada Topik Luas Segiempat

Dari data hasil penelitian diketahui bahwa subjek penelitian hanya menjangkau lapisan formalizing pada topik luas segiempat (Gambar 1). Subjek berangkat untuk memahami luas segiempat (jajargenjang, trapesium, dan layang-layang) dengan membawa bekal primitive 
knowing berupa pengetahuan sebelumnya tentang luas persegipanjang dan konservasi luas. Pada lapisan image making, acting subjek (image doing) berupa kemampuan subjek menggunakan pengetahuan sebelumnya tentang konsep luas dan konsep konservasi luas untuk menggunakan kit tangram (A). Pada lapisan pemahaman ini subjek sudah memahami apa yang dimaksud luas segiempat (jajargenjang, trapesium, dan layang-layang). Expressing subjek (image reviewing) berupa kemampuan mengartikulasikan pemahamannya tentang luas segiempat yang didapatkannya dari aktivitas penggunaan media kit tangram.

Setelah subjek tidak mengalami hambatan apapun dan dapat mengartikulasikan pemahamannya dengan baik, subjek bertumbuh ke lapisan image having. Pada lapisan image having, pemahaman subjek berupa gambaran mental terhadap luas segiempat. Acting subjek (image seeing) berupa kemampuan melihat keterkaitan antara luas segiempat dengan luas persegipanjang untuk dapat menentukan rumus hitung luas bangun tersebut (B). Pada lapisan ini subjek mendapatkan hambatan berupa representasi mental yang tidak utuh terhadap objek yang sedang dipelajari. Pada kesempatan ini peneliti memberikan intervensi berupa petunjuk agar subjek penelitian mampu melakukan self assessment. Setelah mengetahui hambatan yang ditemui, subjek melakukan folding back untuk bekerja kelapisan yang lebih dalam (C). Subjek melakukan folding back ke lapisan image making untuk membantu menemukan informasi yang dapat memperluas pemahamannya dengan merekonstruksi ulang gambaran mental yang dimilikinya (D). Expressing subjek (image saying) berupa kemampuan mengartikulasikan alasan didapatkannya rumus untuk mencari luas segiempat.

Selanjutnya setelah subjek penelitian dapat mengartikulasikan pemahamannya pada lapisan image having, subjek bertumbuh ke lapisan property noticing. Pada lapisan property noticing, acting subjek (property predicting) berupa kemampuan memperhatikan sifat-sifat segiempat untuk menghitung luas segiempat (E). Expressing subjek (property recording) berupa kemampuan mengartikulasikan pemahaman subjek tentang sifat-sifat segiempat dan rumus untuk menghitung luas segiempat tersebut.

Setelah dapat memahami dan mengartikulasikan pemahamannya dengan baik pada lapisan property noticing, subjek penelitian bertumbuh ke lapisan formalizing. Pada lapisan formalizing, acting subjek (method applying) berupa kemampuan melihat karakteristik bangun segiempat dan menggunakannya dalam mencari luas bangun segiempat. Namun sayangnya dalam lapisan pemahaman ini subjek terhambat pada penerapan aktivitas algoritmik dikarenakan kemampuan subjek dalam sifat-sifat operasi hitung kurang baik. Peneliti sudah mencoba memberikan intervensi berupa petunjuk-petunjuk agar subjek penelitian mampu melakukan self assessment, namun subjek gagal untuk melakukan folding back karena informasi yang diinginkan tidak memenuhi kebutuhan subjek. Sehingga subjek terhambat untuk naik ke lapisan pemahaman berikutnya (F). Akibatnya expressing subjek (method justifying) tidak mampu untuk mengartikulasikan aktivitas algoritmik yang dilakukan dan tidak dapat menjangkau lapisan pemahaman berikutnya.

Berdasarkan hasil penelitian tersebut peneliti melihat assessment for learning dalam model pemahaman Pirie \& Kieren pada topik luas segiempat melalui sudut pandang mikro dan makro. Berbagai macam aktivitas yang dapat ditangkap sebagai bagian proses asesmen meliputi self assessment, hambatan pemahaman, folding back, intervensi peneliti, dan bentuk aktivitas acting maupun expressing. Dari sudut pandang assessment for learning secara mikro, kegiatan asesmen dilakukan secara mandiri oleh subjek penelitian melalui self assessment. Kegiatan self assessment tersebut terjadi akibat adanya intervensi dari peneliti yang melihat subjek penelitian mengalami hambatan dalam proses menumbuhkan pemahamannya. Bentuk 
intervensi tersebut berupa petunjuk terhadap permasalahan yang dialami oleh subjek penelitian. Melalui petunjuk tersebut subjek melakukan proses self assessment, dan setelah mengetahui kebutuhannya untuk melanjutkan konstruksi pemahamannya, subjek penelitian melakukan folding back untuk merekonstruksi pemahamannya agar lebih tebal dari sebelumnya.

Proses self assessment yang dilakukan oleh subjek penelitian menunjukkan bahwa pendekatan assessment for learning dalam model pemahaman Pirie \& Kieren dapat berlangsung secara efektif dalam meningkatkan kompetensi subjek penelitian. Dalam kasus ini peningkatan yang terjadi berupa tumbuhnya lapisan pemahaman subjek penelitian pada topik luas segiempat. Di sisi lain peneliti berasumsi pendekatan assessment for learning ini dapat meningkatkan kompetensi lainnya secara komprehensif sesuai dengan desain pembelajaran yang sudah disiapkan (Subali, 2015; Winarno et al., 2019).

Dari sudut pandang assessment for learning secara makro, kegiatan asesmen dilakukan secara holistik oleh peneliti melalui proses refleksi terhadap keseluruhan proses pembelajaran. Proses refleksi tersebut dilaksanakan dengan memanfaatkan umpan balik yang didapatkan selama proses pembelajaran. Peneliti membuat lintasan belajar melalui poin-poin yang ditemukan selama proses refleksi. Proses refleksi yang dilakukan akan menemukan poin-poin utama yang harus dilakukan maupun yang harus diperbaiki pada kegiatan pembelajaran selanjutnya.

Pada lapisan awal (primitive knowing), peneliti akan mendapatkan konsep apa saja yang menjadi pengetahuan awal (prior knowledge) dan harus dikuasai siswa sebelum memulai pembelajaran tersebut. Selanjutnya deskripsi acting dan expressing pada setiap lapisan pemahaman dapat dijadikan acuan penyusunan desain pembelajaran yang tepat. Selain itu hambatan yang dialami subjek serta kegiatan folding back yang dilakukannya dapat menjadi informasi penting tentang apa yang harus disiapkan pada pembelajaran selanjutnya. Dalam kasus ini yang menjadi poin penting adalah penguasaan algoritmik siswa serta media pembelajaran yang tepat dan mampu menumbuhkan representasi visual siswa dengan baik. Poin lainnya yang perlu diperhatikan adalah tentang bagaimana bentuk intervensi yang tepat untuk menghadapi hambatan yang dialami siswa tanpa menghentikan proses konstruksi berpikirnya.

Melalui keseluruhan proses refleksi tersebut, akan didapatkan lintasan belajar yang paling sesuai untuk digunakan dalam pembelajaran luas segiempat selanjutnya. Fakta tersebut menunjukkan bahwa pendekatan assessment for learning dalam model pemahaman Pirie \& Kieren dapat secara efektif digunakan dan dijadikan acuan untuk memperbaiki proses pembelajaran secara berkelanjutan (Budiyono, 2015). Setiap pencapaian lapisan pemahaman dalam teori ini mempunyai karakteristik yang berbeda sesuai topik maupun konsep yang dipelajari (Fauziyyah \& Kriswandani, 2018; Sagala et al., 2018; Safitri et al., 2018). Pendekatan assessment for learning dalam model pemahaman matematika Pirie \& Kieren yang disajikan dalam penelitian ini dapat dijadikan alternatif utama bentuk asesmen pembelajaran agar kualitas pembelajaran dapat meningkat secara berkelanjutan.

Penggunaan pendekatan assessment for learning dalam model pemahaman matematika Pirie \& Kieren dalam penelitian ini memunculkan suatu paradigma baru dalam dunia asesmen pembelajaran matematika di sekolah dasar. Tentu saja temuan penelitian ini akan mendapatkan respon yang beragam sesuai dengan perbedaan karakteristik siswa dalam pembelajaran matematika. Sehingga temuan penelitian ini masih harus dikonfirmasi kembali dengan penelitian lainnya. Oleh karena itu peneliti akan terus mengembangkan temuan ini 
dengan subjek dan topik yang lebih beragam dalam pembelajaran matematika di sekolah dasar.

\section{Kesimpulan}

Berdasarkan hasil penelitian dan pembahasan dapat disimpulkan bahwa bentuk assessment for learning dalam model pemahaman Pirie \& Kieren pada pembelajaran matematika topik luas segiempat dapat dilihat dari dua sudut pandang, yaitu mikro dan makro. Bentuk assessmen for learning dari sudut pandang mikro berupa kegiatan self assessment yang dilakukan siswa selama proses pembelajaran berlangsung. Proses self assessment tersebut dilakukan pada tiap-tiap lapisan pemahaman. Syarat utama pertumbuhan pada setiap lapisan pemahaman adalah kemampuan siswa mengartikulasikan pemahamannya baik secara tertulis maupun lisan. Bentuk assessment for learning dari sudut pandang makro berupa kegiatan refleksi secara holistik oleh guru terhadap keseluruhan rangkaian proses pembelajaran. Refleksi dilakukan guru dengan bertindak sebagai peneliti untuk mengamati poin-poin kritis dan terperinci. Poinpoin tersebut dianalisis sedemikian rupa hingga menghasilkan lintasan belajar ideal pada topik yang diinginkan. Melalui hasil refleksi tersebut guru akan mendapatkan poin-poin penting yang dapat digunakan untuk memperbaiki proses pembelajaran secara berkelanjutan. Kedua bentuk assessmen for learning tersebut merupakan alternatif asesmen pembelajaran yang sangat ideal untuk diimplementasikan dalam pembelajaran matematika di sekolah dasar.

\section{Daftar Pustaka}

Ayuningsih, D., Kristin, F., \& Anugraheni, I. (2019). PENERAPAN MODEL PEMBELAJARAN PROBLEM BASED LEARNING (PBL) UNTUK MENINGKATKAN HASIL BELAJAR DAN BERPIKIR KRITIS MATEMATIKA. Jurnal Cakrawala Pendas, 5(2). https://doi.org/10.31949/jcp.v5i2.1351

Bird, F. L., \& Yucel, R. (2013). Improving marking reliability of scientific writing with the Developing Understanding of Assessment for Learning programme. Assessment \& Evaluation in Higher Education, 38(5), 536-553. https://doi.org/10.1080/02602938.2012.658155

Budiyono. (2015). Pengantar Penilaian Hasil Belajar. UNS Press.

Carless, D. (2017). Students' Experiences of Assessment for Learning. In G. R. Carless D., Bridges S., Chan C. (Ed.), Scaling up Assessment for Learning in Higher Education. The Enabling Power of Assessment.

Fauziyyah, F. A., \& Kriswandani, K. (2018). Description Profile of Understanding Layer Concept of Conic Section of Mathematics Education Students 2016 of FKIP UKSW. In Proceedings of the 1st Annual International Conference on Mathematics, Science, and Education (ICoMSE 2017). Atlantis Press. https://doi.org/10.2991/icomse-17.2018.5

Gall, M. D., Gall, J. P., \& Borg, W. (2003). Educational Research: An Introduction (7th Edition). Pearson Education.

Gulkilik, H., Moyer-packenham, P. S., \& Ugurlu, H. H. (2020). Characterizing the growth of one student' $s$ mathematical understanding in a multi-representational learning environment. Journal of Mathematical Behavior, 58. https://doi.org/10.1016/j.jmathb.2020.100756

Hill, L., \& Edwards, F. (2019). Student perceptions of their involvement in formative assessment feedback practices: "I can do it myself." Assessment Matters, 13, 6-43. https://doi.org/10.18296/am.0036

Kieren, T. E., \& Pirie, S. E. B. (1991). Recursion and the Mathematical Experience. In Recent Research in Psychology (pp. 78-101). Springer New York. https://doi.org/10.1007/978-14612-3178-3_6 
Martin-Kniep, G. O., \& Shubert, R. (2017). Learning That's Made to Measure. The Learning Professional, 38(2).

Martin, L. C. (2008). Folding back and the dynamical growth of mathematical understanding: Elaborating the Pirie-Kieren Theory. The Journal of Mathematical Behavior, 27(1), 64-85. https://doi.org/10.1016/j.jmathb.2008.04.001

Martin, L., LaCroix, L., \& Fownes, L. (2005). Flexible Mathematical Understanding in an Ironworking Apprenticeship Classroom. Literacy and Numeracy Studies, 15(1), 45-60. https://doi.org/10.5130/lns.v15i1.2026

Pirie, S., \& Kieren, T. (1994). Growth in Mathematical Understanding: How Can We Characterise It and How Can We Represent It? In Learning Mathematics (pp. 61-86). Springer Netherlands. https://doi.org/10.1007/978-94-017-2057-1_3

Pirie, S., \& Martin, L. (2000). The role of collecting in the growth of mathematical understanding. Mathematics Education Research Journal, 12(2), 127-146. https://doi.org/10.1007/bf03217080

Sadler, D. R. (1989). Formative assessment and the design of instructional systems. Instructional Science, 18(2), 119-144. https://doi.org/10.1007/bf00117714

Safitri, R. I., Mulyani, S., \& Ratu, N. (2018). Profil Lapisan Pemahaman Konsep Siswa SMP Terkait Garis Tinggi Segitiga. Jurnal Ilmiah Soulmath: Jurnal Edukasi Pendidikan Matematika, 6(2), 65. https://doi.org/10.25139/smj.v6i2.1141

Sagala, V., Kusmiyati, K., \& Sucipto, S. (2018). Peningkatan Lapisan Pemahaman Konsep Bangun Datar Mahasiswa Calon Guru dengan Penerapan Model Pembelajaran PRAKTAK. MUST: Journal of Mathematics Education, Science and Technology, 3(2), 152. https://doi.org/10.30651/must.v3i2.1845

Sawant, D. G. (2016). Role of IQAC in maintaining quality standards in teaching, learning and evaluation. Pacific Science Review B: Humanities and Social Sciences, 2(2), 66-69. https://doi.org/10.1016/j.psrb.2016.09.016

Sengul, S., \& Yildiz, S. G. (2016). An Examination of the Domain of Multivariable Functions Using the Pirie-Kieren Model. Universal Journal of Educational Research, 4(7), 1533-1544. https://doi.org/10.13189/ujer.2016.040706

Subali, B. (2015). PENGUKURAN KREATIVITAS KETERAMPILAN PROSES SAINS DALAM KONTEKS ASSESSMENT FOR LEARNING. Jurnal Cakrawala Pendidikan, 1(1). https://doi.org/10.21831/cp.v1i1.4196

Syamsuri, S., Marethi, I., \& Mutaqin, A. (2018). UNDERSTANDING ON STRATEGIES OF TEACHING MATHEMATICAL PROOF FOR UNDERGRADUATE STUDENTS. Jurnal Cakrawala Pendidikan, 37(2). https://doi.org/10.21831/cp.v37i2.19091

Thomson, R. (2013). Implementation of criteria and standards-based assessment: an analysis of first-year learning guides. Higher Education Research \& Development, 32(2), 272-286. https://doi.org/10.1080/07294360.2012.676026

Valcare, M. C., Martín, M. L. D., Astudillo, M. T. G., \& Pérez, M. C. M. (2013). Comprensión del concepto de serie numérica a través del modelo de Pirie y Kieren. Enseñanza de Las Ciencias, 31(3), 135-154. https://doi.org/10.5565/rev/ec/v31n3.963

Winarno, W., Zuhri, M., Mansur, M., Sutomo, I., \& Widhyahrini, K. (2019). Development of Assessment for the Learning of the Humanistic Model to Improve Evaluation of Elementary School Mathematics. International Journal of Instruction, 12(4), 49-64. https://doi.org/10.29333/iji.2019.1244a

Wright, V. (2014). Frequencies as proportions: Using a teaching model based on Pirie and Kieren's model of mathematical understanding. Mathematics Education Research Journal, 26(1), 101-128. https://doi.org/10.1007/s13394-014-0118-7

Wulandari, S. P. (2016). Menciptakan Kemandirian Belajar Siswa Melalui Pembelajaran Berbasis Discovery Learning dengan Assessment for Learning. PRISMA, Prosiding Seminar Nasional Matematika, 226-232.

Yanto, A., Yuliati, Y., \& Anjani, T. (2020). Pengaruh Pendekatan Matematika Realistik terhadap Pemahaman Matematis Siswa. Jurnal Elementaria Edukasia, 3(1), 92-102. 